\section{A) Check for updates}

Cite this: Polym. Chem., 2019, 10 963

Received 4th December 2018 Accepted 14th January 2019

DOI: 10.1039/c8py01720d

rsc.li/polymers

\title{
Ultra-low volume oxygen tolerant photoinduced Cu-RDRP $\uparrow$
}

\author{
Evelina Liarou, (D) Athina Anastasaki, (D) Richard Whitfield, (ID Carmelo E. lacono, \\ Georgios Patias, Nikolaos G. Engelis, Arkadios Marathianos, (D) Glen R. Jones (D) and \\ David M. Haddleton (D) *
}

\begin{abstract}
We introduce the first oxygen tolerant ultra-low volume (as low as $5 \mu \mathrm{L}$ total reaction volume) photoinduced copper-RDRP of a wide range of hydrophobic, hydrophilic and semi-fluorinated monomers including lauryl and hexyl acrylate, poly(ethylene glycol methyl ether acrylate) and trifluoroethyl (meth) acrylates. In the absence of any external deoxygenation, well-defined homopolymers can be obtained with low dispersity values, high end-group fidelity and near-quantitative conversions. Block copolymers can be efficiently synthesized in a facile manner and the compatibility of the system to larger scale polymerizations (up to $0.5 \mathrm{~L}$ ) is also demonstrated by judiciously optimizing the reaction conditions. Importantly, the online monitoring of oxygen consumption was also conducted through an oxygen probe and the role of each component is identified and discussed.
\end{abstract}

\section{Introduction}

The development of reversible-deactivation radical polymerization (RDRP) has amplified the field of polymer synthesis providing access to the synthesis of well-defined polymeric materials, in high yields, with different architectures and unlimited functionality. ${ }^{1-12}$ Typically, all RDRP techniques (e.g. atom-transfer radical polymerization (ATRP), ${ }^{13,14}$ single electron transfer-living radical polymerization (SET-LRP), ${ }^{8,15}$ reversible addition-fragmentation chain-transfer polymerization (RAFT), ${ }^{16-18}$ nitroxide-mediated polymerization (NMP) ${ }^{19,20}$ etc.) rely on intensive deoxygenation techniques including the use of glove box equipment, freeze-pump-thaw cycles or inert gas sparging to reduce (and ideally eliminate) the presence of oxygen. Oxygen is reported to be detrimental for radical polymerizations since it acts as an efficacious radical scavenger, rapidly reacting with carbon-centred radicals (both initiating and propagating radicals), and eventually leading to peroxy radicals and hydroperoxides which are inefficient at reinitiating the polymerization. ${ }^{21-24}$

Although traditional deoxygenation techniques are efficacious for the complete removal of oxygen, they can also be disadvantageous in some cases. For instance, the use of glove box equipment is a sophisticated, albeit expensive and time-consuming approach which also requires extensive training prior

University of Warwick, Department of Chemistry, Library Road, Coventry, CV4 7AL, UK. E-mail:d.m.haddleton@warwick.ac.uk

$\dagger$ Electronic supplementary information (ESI) available. See DOI: 10.1039/ c8py01720d to use. Freeze-pump-thaw is another costly and time-consuming deoxygenation method which can also be problematic when proteins or enzymes are involved, leading to denaturation and loss of their secondary structure. ${ }^{25}$

Finally, inert gas sparging with either argon or nitrogen (socalled "bubbling") is perhaps the most popular and convenient method to remove oxygen from polymerization solutions. However, sparging can lack reproducibility as it may alter the concentration of volatiles and precludes the use of low sample volumes. In addition, all the existing deoxygenation methods may not be available in all laboratories and/or add complexity to the set-up, thus restricting the accessibility to non-experts.

To mitigate this arduous task of conventional deoxygenation, many groups have exploited the use of enzymes to deoxygenate controlled radical polymerization. ${ }^{26-30}$ For example, Chapman et al. were the first to use glucose oxidase (GOx) to remove oxygen in a RAFT polymerization where narrow molecular weight distributions were achieved even when the experiments were performed in open vessels. ${ }^{31,32}$ In the case of ATRP, Matyjaszewski and co-workers subsequently reported the first controlled aqueous ATRP in an open vessel which was coined as "breathing ATRP". ${ }^{29}$ In their system, GOx was employed to continuously remove oxygen from the polymerization solution. Alternative strategies to deoxygenate controlled radical polymerizations include the use of various reducing agents such as triethylamine, ${ }^{33,34}$ hydrazine ${ }^{35,36}$ and ascorbic acid. $^{37,38}$

Among the various oxygen tolerant polymerization strategies, photoinduced electron-transfer (PET)-RAFT is arguably one of the most popular. ${ }^{39}$ The use of light, in particular, has 
attracted considerable interest due to the polymerizations proceeding under conditions milder than conventional thermal approaches, it is non-invasive and environmentally benign, and gives the potential for spatiotemporal control. ${ }^{19,40-42}$ Boyer and co-workers first reported the oxygen tolerance of PET-RAFT in which the oxygen can be consumed by either a photocatalyst or a reducing agent. Examples of photocatalysts include $\left(\right.$ fac- $\left.\left[\operatorname{Ir}(\mathrm{ppy})_{3}\right]\right),{ }^{43}$ zinc tetraphenylporphine $(\mathrm{ZnTPP})^{44}$ and Eosin $\mathrm{Y}^{38}$ while ascorbic acid ${ }^{37,38}$ and triethylamine ${ }^{45}$ are the most commonly employed reducing agents. The strong reducing ability of the photocatalysts facilitates the oxygen removal prior to polymerization. ${ }^{24,46,47}$ This is particularly important for low-scale polymerizations and combinatorial synthesis. The ability to conduct polymerizations in extremely low volumes (typically from $20 \mu \mathrm{L}$ to $500 \mu \mathrm{L}$ ) is an area of growing academic interest as it allows for the inexpensive, fast and high throughput screening of a wide range polymeric materials. ${ }^{24}$ To date, PET-RAFT is the main controlled radical polymerization method that has been utilized for the high throughput synthesis of a range of polymeric materials. ${ }^{39}$ However, examples of oxygen tolerant photoinduced ATRP are very limited. ${ }^{33,48-51}$ To the best of our knowledge, there is no report on the use of any copper-mediated controlled radical polymerization method to afford the controlled synthesis of polymeric materials at very low volumes. This is a significant oversight given the high efficiency of Cu-RDRP to synthesize a wide range of complex polymeric materials with controlled functionality, dispersity and architecture (e.g. stars, multiblocks etc.). ${ }^{1,4,6}$ In addition, the key role of each component in oxygen consumption during photoinduced copper mediated radical polymerization has not been identified and clarified.

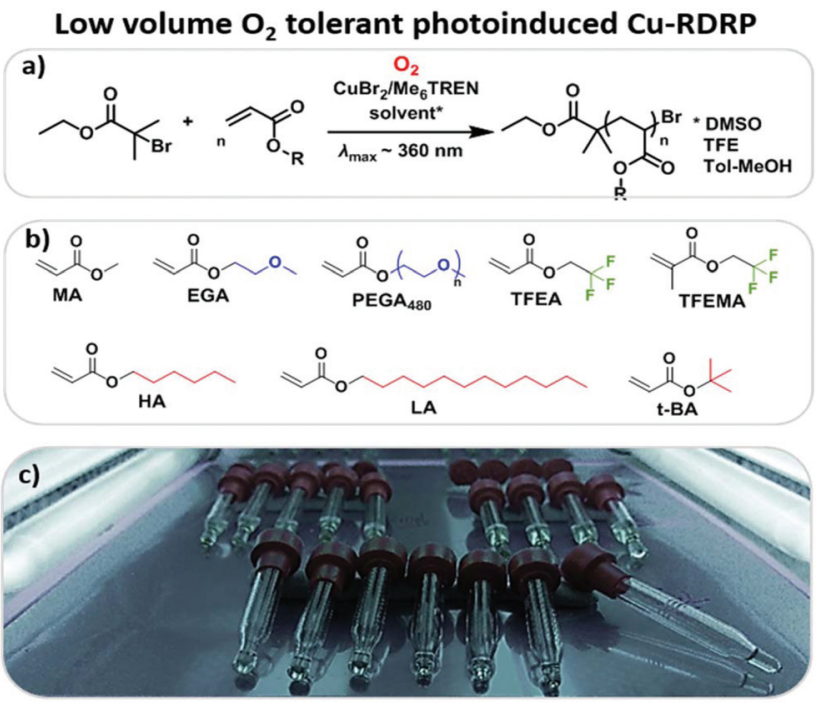

Scheme 1 a) Typical reaction scheme for the low volume oxygen tolerant photoinduced-RDRP, (b) different hydrophobic, hydrophilic and semi-fluorinated monomers employed and (c) low volume reaction setup utilizing commercially available glass inserts and a UV nail lamp with broad band $\lambda_{\max } \sim 360 \mathrm{~nm}$.
In this contribution, photoinduced $\mathrm{Cu}-\mathrm{RDRP}$ is conducted in the absence of any external deoxygenation methods. Subsequently, the polymerization of a range of monomers with different polarity is carried out at very low volumes (Scheme 1), and the capability of the system to afford chain extensions is explored. The scalability of this approach to higher volume polymerizations (up to $0.5 \mathrm{~L}$ ) is also reported. Finally, an oxygen probe for the in situ online monitoring of oxygen consumption during photoinduced controlled radical polymerization is employed, aiming to identify the role of the reaction components in oxygen consumption. Finally, the scalability of our approach to higher volume polymerizations (up to $0.5 \mathrm{~L}$ ) is explored.

\section{Results and discussion}

Initially, we explored the possibility of photoinduced Cu-RDRP to operate in a controlled manner, in the absence of external deoxygenation. For this study, methyl acrylate (MA) was employed as the monomer, dimethyl sulfoxide (DMSO) as the solvent, tris(2-(dimethylamino)ethyl)-amine ( $\mathrm{Me}_{6}$ Tren) as the ligand, ethyl $\alpha$-bromoisobutyrate (ЕBiB) as the initiator with $\mathrm{Cu}(\mathrm{II}) \mathrm{Br}_{2}$ as the copper source, following the ratio $[\mathrm{MA}]:[\mathrm{I}]:\left[\mathrm{CuBr}_{2}\right]:\left[\mathrm{Me}_{6}\right.$ Tren $]=[50]:[1]:[0.02]:[0.12]$ under a UV "nail lamp" with a broad band $\lambda_{\max } \sim 360 \mathrm{~nm}$. Preliminary experiments were conducted on an $8 \mathrm{~mL}$ reaction scale with $50 \% \mathrm{v} / \mathrm{v}$ DMSO. Inspired by our previous investigation using $\mathrm{Cu}(0)$ wire-mediated RDRP where the elimination of headspace was the crucial step to achieve an oxygen tolerant system, ${ }^{52}$ we left the polymerization to commence in a fully filled vial, capped with a lid. In the absence of any type of commonly applied deoxygenation method and without any externally added reducing agents, 98\% monomer conversion was achieved, leading to $\mathrm{PMA}_{50}$ with narrow molecular weight distribution $(\nexists \sim 1.08)$ and good agreement between the theoretical $\left(M_{\mathrm{n}, \mathrm{th}}=4400\right)$ and the experimental molecular weight $\left(M_{\mathrm{n}, \mathrm{SEC}}=4900\right)$ (Fig. 1a). Importantly, the resulting polymer exhibited negligible differences when compared to an identical experiment in which $\mathrm{N}_{2}$ sparging was applied prior to polymer-
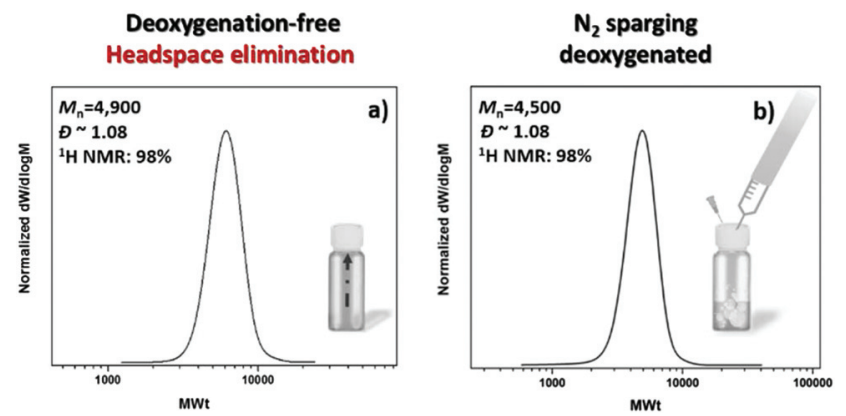

Fig. 1 SEC traces of (a) the non-deoxygenated $\mathrm{PMA}_{50}$ and (b) the $\mathrm{N}_{2}$ sparging-deoxygenated $\mathrm{PMA}_{50}$ both synthesized via photoinduced $\mathrm{Cu}$ RDRP with [MA]: [EBiB] : [Cu(॥)Br 2$]:\left[\mathrm{Me}_{6}\right.$ Tren] = [50]: [1]:[0.02]:[0.12] under a UV nail lamp with broad band $\lambda_{\max } \sim 360 \mathrm{~nm}$. 
ization (Fig. 1b). The slight deviation in the final molecular weights $(<10 \%)$ can be attributed to the small amount of dissolved oxygen within the polymerization solution which is consistent with previous literature. ${ }^{52}$ A detailed description of the oxygen consumption is provided in the final section of this manuscript.

The possibility of conducting controlled polymerizations in the presence of oxygen can potentially enable the high throughput synthesis of a wide range of polymers at low reaction volumes. In order to test this hypothesis, commercially available vial inserts with a full capacity of $200 \mu \mathrm{L}$ were utilized and all the reactions were sealed with lids (Fig. S1†). To eliminate the headspace, the vial insert was initially fully filled with the reaction solution $(200 \mu \mathrm{L} / 200 \mu \mathrm{L})$ (Fig. 2a). Under these conditions, PMA with degree of polymerization (DP) 50 was targeted, yielding well-defined PMA, with near-quantitative monomer conversion (96\%, Fig. S2 $\dagger$ ), low dispersity and symmetrical size exclusion chromatography (SEC) traces $(\nexists \sim 1.07$, $M_{\text {n,exp }} \sim 5200$ ).

Encouraged by these initial findings, we then lowered the reaction volume from $200 \mu \mathrm{L}$ to $60,40,20,10$ and $5 \mu \mathrm{L}$ (Fig. 2 (a-d) and Fig. $\mathrm{S} 3 \dagger$ ). For these experiments, we maintained the $200 \mu \mathrm{L}$ commercially available vial inserts, in which the headspace was increased from zero to 140, 160, 180, 190 and $195 \mu \mathrm{L}$, respectively. Despite the increase of the headspace, all polymerizations reached near-quantitative conversions (>96\%) without compromising the control over the molecular weight and the molecular weight distributions $(\nexists \sim 1.1)$. In all cases, comparable initiator efficiencies were observed $\left(M_{\mathrm{n}, \mathrm{SEC}} \sim\right.$ 5000-5500) indicating that in DMSO, the headspace has only negligible effects, if any, on the targeted molecular weight (Fig. 2 and Table 1). This is in contrast with other coppermediated approaches where the headspace has been reported to play an important role. $^{52}$ This may be attributed to the
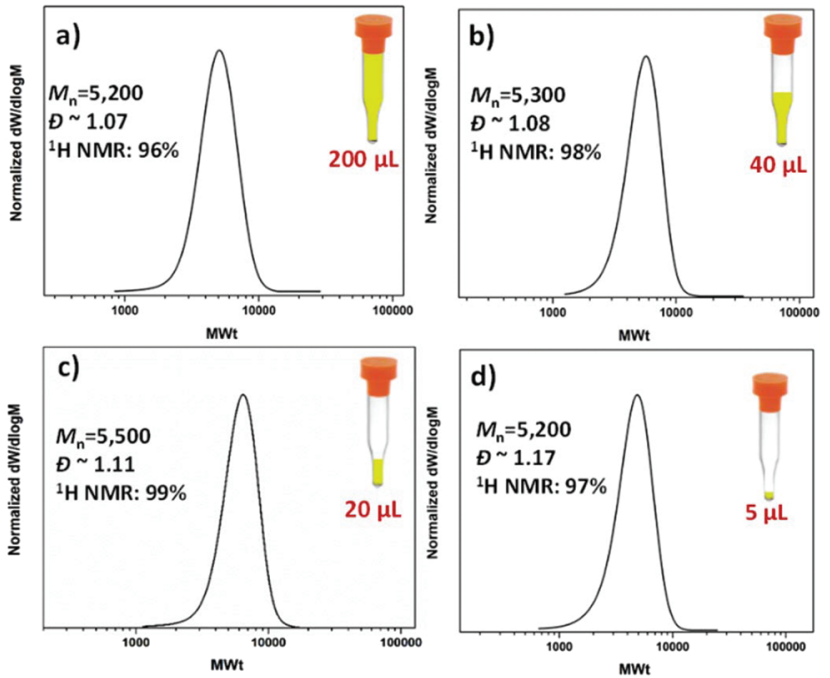

Fig. 2 SEC traces for $\mathrm{PMA}_{50}$ with (a) $200 \mu \mathrm{L}$ (b) $40 \mu \mathrm{L}$, (c) $20 \mu \mathrm{L}$ and (d) $5 \mu \mathrm{L}$ reaction volume synthesized via oxygen tolerant photoinduced $\mathrm{Cu}$ RDRP with [MA] : [EBiB]: [Cu(॥)Br 2$]:\left[\mathrm{Me}_{6}\right.$ Tren] = [50]:[1]:[0.02]:[0.12] using a UV lamp with broad band $\lambda_{\max } \sim 360 \mathrm{~nm}$.
Table $1{ }^{1} \mathrm{H}$ NMR and SEC analysis for the low volume $\mathrm{PMA}_{50}$ obtained with different headspaces in the absence of deoxygenation ${ }^{a}$

\begin{tabular}{lccccc}
\hline $\begin{array}{l}\text { Scale } \\
(\mu \mathrm{L})\end{array}$ & $\begin{array}{c}\text { Headspace } \\
(\mu \mathrm{L})\end{array}$ & $\begin{array}{c}\text { Conversion } \\
{ }^{1} \mathrm{H} \text { NMR }(\%)\end{array}$ & $\begin{array}{c}M_{\mathrm{n}}, \text { theory } \\
\left(\mathrm{g} \mathrm{mol}^{-1}\right)\end{array}$ & $M_{\mathrm{n}, \mathrm{SEC}}{ }^{b}$ & $D$ \\
\hline 200 & 0 & 96 & 4300 & 5200 & 1.07 \\
60 & 140 & 98 & 4400 & 5400 & 1.08 \\
40 & 160 & 98 & 4400 & 5300 & 1.08 \\
20 & 180 & 99 & 4500 & 5500 & 1.11 \\
10 & 190 & 99 & 4500 & 5000 & 1.11 \\
5 & 195 & 97 & 4400 & 5200 & 1.17
\end{tabular}

${ }^{a}$ In all polymerizations, the volume ratio of monomer to solvent was maintained $1: 1$ and conversion was calculated via ${ }^{1} \mathrm{H}$ NMR. ${ }^{b}$ Determined by THF SEC analysis and expressed as molecular weight equivalents to PMMA narrow molecular weight standards.

absence of stirring in this system which limits the diffusion of oxygen into the polymerization solution. It should also be highlighted that even at ultra-low volumes (i.e. $5 \mu \mathrm{L}$ ), the polymerization proceeds efficiently, although with slightly higher dispersity values $(\nexists \sim 1.17)$. To the best of our knowledge, this is the lowest scale reported for controlled radical polymerization to date. The low volume experiments were also conducted with $\sim 300 \mathrm{ppm}$ of copper. Importantly, we could further reduce the concentration to $37 \mathrm{ppm}$ without significantly compromising the control over the molecular weight distributions (Fig. $\mathrm{S} 4 \dagger$ ).

To explore the extent of control over higher molar masses, a range of different degrees of polymerization (100-400) were investigated. All polymerizations were performed on a $60 \mu \mathrm{L}$ scale. Well-defined PMAs up to DP $=400$ were obtained with final $M_{\mathrm{n}, \mathrm{SEC}}=38500$ and a dispersity of 1.19 at high monomer conversions ( $>82 \%$ ) (Fig. 3 and Table 2). Unfortunately, targeting higher DPs (i.e. 600 and 800) resulted in no conversion, even when the reaction was left to proceed overnight. This was attributed to the low initiator and catalyst concentrations and will be further discussed in the mechanistic section of this paper. We were then interested in expanding the scope of the

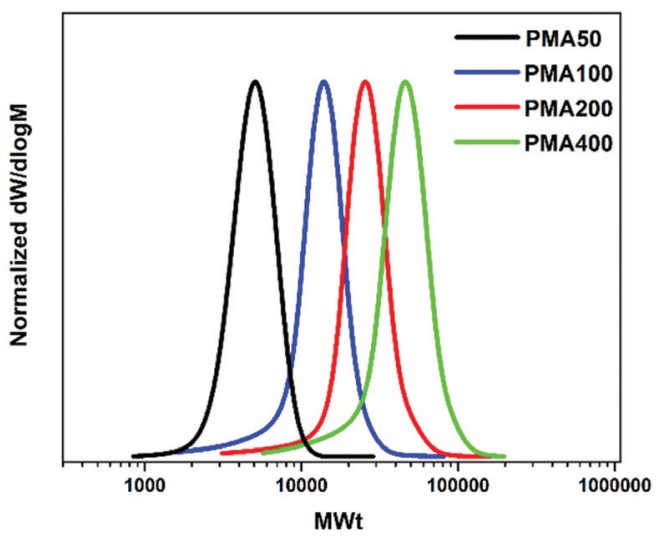

Fig. 3 SEC traces for the low-scale oxygen-tolerant photoinduced $\mathrm{Cu}$ RDRP of MA with targeted DPs 50-400 and [MA]:[EBiB]: [Cu(॥) $\left.\mathrm{Br}_{2}\right]:\left[\mathrm{Me}_{6} \mathrm{Tren}\right]=\left[\mathrm{DP}_{n}\right]:[1]:[0.02]:[0.12]$ under a UV lamp with broad band $\lambda_{\max } \sim 360 \mathrm{~nm}$. 
Table $2{ }^{1} \mathrm{H}$ NMR and SEC analysis for low volume PMA with different targeted DPs obtained via photoinduced Cu-RDRP in the absence of deoxygenation $^{a}$

\begin{tabular}{lcccc}
\hline DP & Conversion ${ }^{1} \mathrm{H}$ NMR $(\%)$ & $M_{\text {n, th. }}\left(\mathrm{g} \mathrm{mol}^{-1}\right)$ & $M_{\mathrm{n}, \mathrm{SEC}}{ }^{b}$ & $D$ \\
\hline 50 & 98 & 4400 & 5400 & 1.08 \\
100 & 99 & 8700 & 11000 & 1.18 \\
200 & 92 & 16000 & 23000 & 1.19 \\
400 & 82 & 24800 & 38500 & 1.19
\end{tabular}

${ }^{a}$ In all polymerizations the volume ratio of monomer to solvent was maintained $1: 1$ and conversion was calculated via ${ }^{1} \mathrm{H}$ NMR. ${ }^{b}$ Determined by THF SEC analysis and expressed as molecular weight equivalents to PMMA narrow molecular weight standards. low volume photoinduced $\mathrm{Cu}$-RDRP to a wide range of hydrophobic, hydrophilic and semi-fluorinated monomers. Given the tolerance of the methodology in the presence of large headspace when DMSO was used as a solvent, ethylene glycol methyl ether acrylate (EGA) was polymerized efficiently at $10 \mu \mathrm{L}$ scale with $M_{\mathrm{n}, \mathrm{SEC}}=7300$ and $D \sim 1.17$ at $99 \%$ conversion (Fig. 4a, Fig. S5† and Table 3). Polymerization of the hydrophilic poly(ethylene glycol) methyl ethyl acrylate $\left(\mathrm{PEGA}_{480}\right)_{20}$ also afforded a well-defined polymer at high conversion $(>99 \%)$ with narrow molecular weight distributions $(D \sim 1.18)$ (Fig. 4b, Fig. S6 $\dagger$ and Table 3). These results further highlight the versatility of DMSO to enable the synthesis of controlled polymers at very high conversions and ultra-low reaction volumes, ${ }^{53}$ even in the presence of headspace.
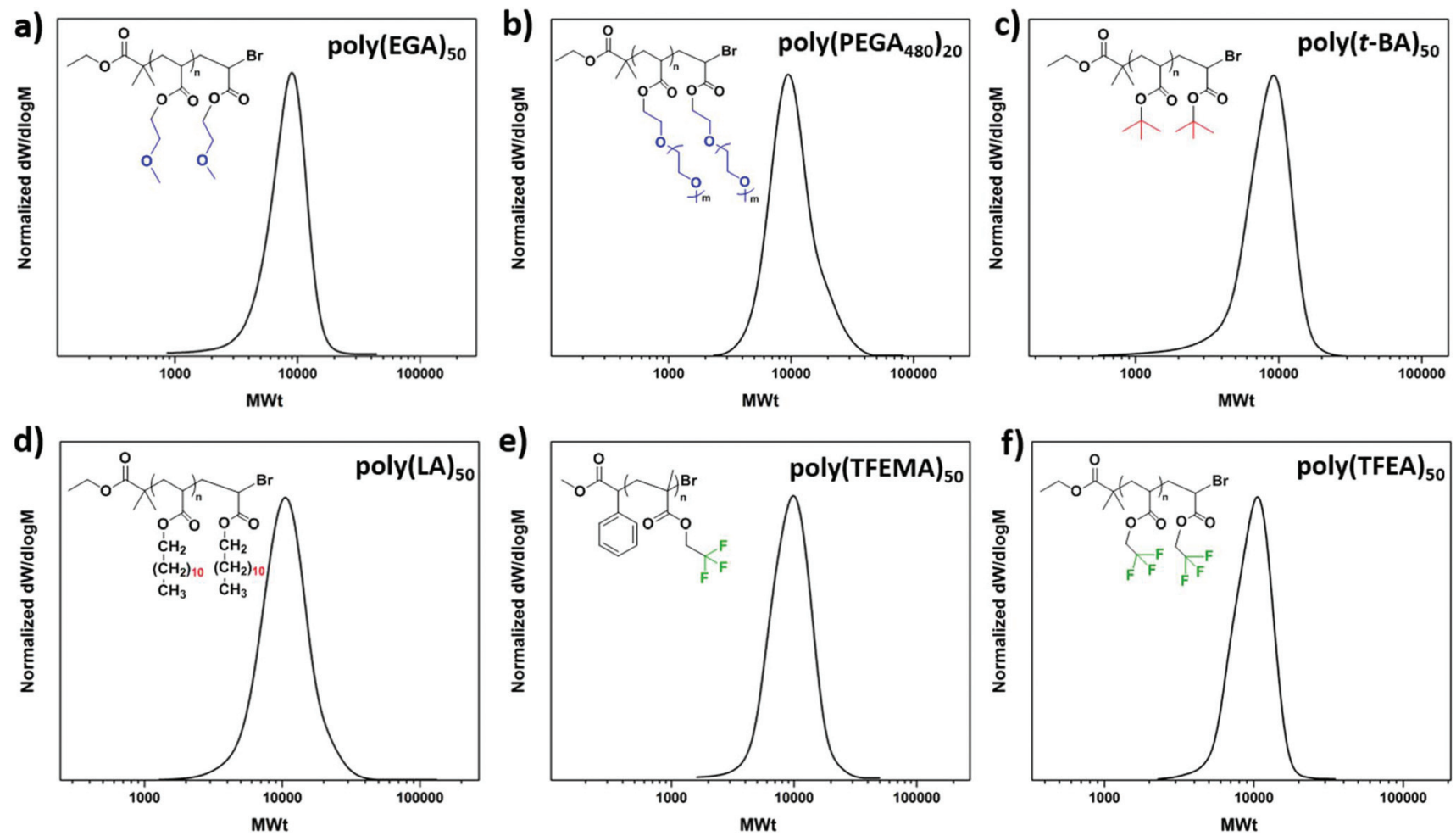

Fig. 4 SEC traces for (a) poly(EGA) $)_{50}$, (b) poly $\left(\mathrm{PEGA}_{480}\right)_{20}$, (c) poly $(t-B A)_{50}$, (d) poly $(\mathrm{LA})_{50}$, (e) poly $(\mathrm{TFEMA})_{50}$ and (f) poly(TFEA) 50 obtained through low-volume deoxygenation-free photoinduced Cu-RDRP.

Table $3{ }^{1} \mathrm{H}$ NMR and SEC analysis for all the different polymers obtained through photoinduced Cu-RDRP without any type of deoxygenation ${ }^{a}$

\begin{tabular}{|c|c|c|c|c|c|c|c|}
\hline Polymer & Scale $(\mu \mathrm{L})$ & Solvent & DP & Conversion ${ }^{1} \mathrm{H}$ NMR, \% & $M_{\mathrm{n}, \text { theory }}\left(\mathrm{g} \mathrm{mol}^{-1}\right)$ & $M_{\mathrm{n}, \mathrm{SEC}}^{b}$ & 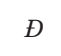 \\
\hline $\mathrm{P}\left(\mathrm{PEGA}_{480}\right)$ & 10 & DMSO & 20 & 99 & 9500 & 9300 & 1.18 \\
\hline $\mathrm{P}(t-\mathrm{BA})$ & 100 & Tol-MeOH & 50 & 97 & 6400 & 7000 & 1.2 \\
\hline PHA & 100 & TFE & 50 & 93 & 7400 & 7600 & 1.19 \\
\hline PTFEA & 100 & TFE & 50 & 99 & 7900 & 8900 & 1.08 \\
\hline
\end{tabular}

${ }^{a}$ In all polymerizations the volume ratio of monomer to solvent was maintained $1: 1$ and conversion was calculated via ${ }^{1} \mathrm{H}$ NMR. ${ }^{b}$ Determined by THF SEC analysis and expressed as molecular weight equivalents to PMMA narrow molecular weight standards. 
Owing to the diverse properties of hydrophobic ${ }^{54-57}$ and semi-fluorinated ${ }^{58,59}$ materials we were then interested in polymerizing tert-butyl (t-BA), hexyl (HA, C6), lauryl (LA, C12) and trifluoroethyl (meth)acrylates (TFEA and TFEMA). However, DMSO has been reported as an unsuitable solvent leading to insoluble final polymeric materials and subsequent loss of control. ${ }^{60,61}$ As an alternative, the polymerization of $t$-BA and LA was attempted in mixtures of toluene/MeOH $(4: 1)$, where a small amount of $\mathrm{MeOH}$ is necessary to facilitate the complete solubilization of the catalyst, while toluene is needed to dissolve the monomers and the resulting polymers. Unfortunately, in the presence of a large headspace $(10 \mu \mathrm{L}$ reaction scale in a $200 \mu \mathrm{L}$ vial insert) no polymerization was observed within $24 \mathrm{~h}$ for either $t$-BA or LA. Moreover, when the polymerization of MA was conducted in the same solvent system, similarly to the other monomers, no monomer conversion occurred. However, when the identical experiments were performed upon elimination of the headspace to almost zero, the polymerization of $t$-BA (Fig. 4c, Fig. S7† and Table 3), LA (Fig. 4d and Table 3) and MA (Fig. S8 and Table S1 $\dagger$ ) occurred in a controlled manner, exhibiting narrow molecular weight distributions. In a similar vein, the polymerization of HA and TFEA, as well as MA in the presence of a large headspace and in trifluroethanol (TFE) was unsuccessful, and no polymerization was observed. On the contrary, when the low scale polymerizations took place in full vial inserts, control over the polymerization was maintained leading to $\mathrm{PHA}_{50}$ (Fig. S9a, $\mathrm{b} \dagger$ and Table 3), $\mathrm{PMA}_{50}$ (Fig. S10 and Table S1 $\dagger$ ) and PTFEA (Fig. 4f, Fig. S11† and Table 3) with low dispersities. Interestingly, although the polymerization of TFEA was unsuccessful in the presence of headspace, the methacrylate analogue (TFEMA) was polymerized with $\sim 90 \mu \mathrm{L}$ headspace, yielding a well-defined PTFEMA $A_{50}$ with $M_{\mathrm{n}, \mathrm{SEC}}=8400$ and $D \sim 1.15$ (Fig. 4e, Fig. S12† and Table 3).

The ability of the semi-fluorinated methacrylate to undergo polymerization even in the presence of significant headspace, was attributed to the higher degree of oxygen tolerance for the methacrylates compared to acrylates. ${ }^{62}$ Overall, these experiments suggest that both toluene/ $\mathrm{MeOH}$ mixture and TFE possess limited headspace tolerance. The limited headspace tolerance of TFE might not be surprising given the capability of fluorinated and semi-fluorinated solvents to act as oxygen carriers. ${ }^{63}$ Nevertheless, by eliminating the headspace, the polymerizations proceeded in a controlled manner in all attempted solvents allowing for the low volume polymerization of a wide range of materials at high conversions.

To investigate the extent of end-group fidelity for the photoinduced low volume RDRP experiments, matrix-assisted laser desorption/ionization time of flight (MALDI-ToF) mass spectrometry was employed to analyze PMA with targeted DP $=25$. A predominant polymer peak distribution was identified corresponding to polymer chains initiated by EBiB and terminated by the desired bromine end-group (Fig. $5 \mathrm{a}$ ).

This suggests that active end-groups can be maintained during polymerization which prompted us to attempt in situ chain extensions. However, upon chain extending PMA with an
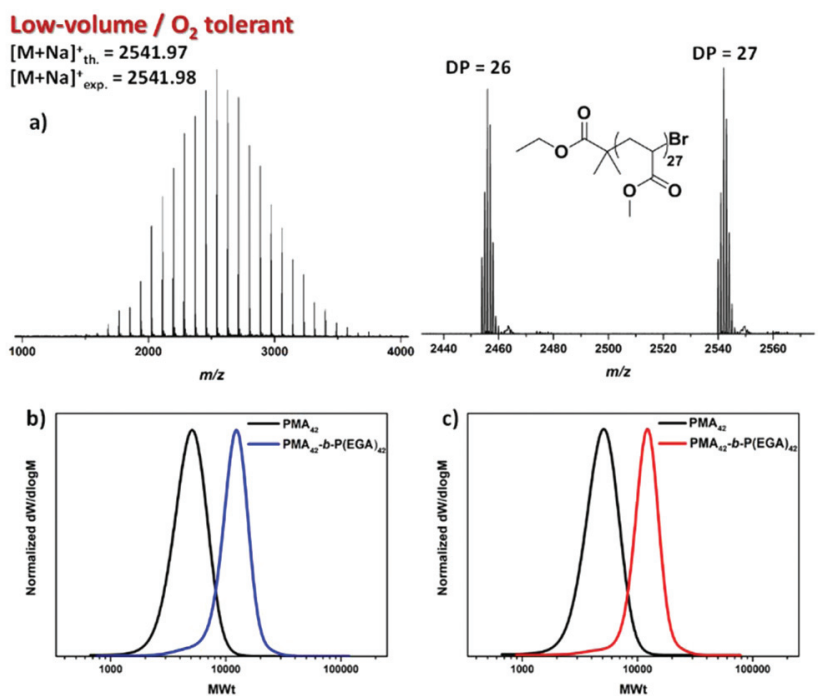

Fig. 5 (a) MALDI-ToF spectrum for the deoxygenation-free $10 \mu \mathrm{L}$ $\mathrm{PMA}_{25}$ revealing the predominant single peak distribution and SEC traces for the diblocks $\mathrm{P}(\mathrm{MA})_{42}-b-\mathrm{P}(\mathrm{EGA})_{42}$ on a (b) $200 \mu \mathrm{L}$ scale (absence of headspace) and (c) $20 \mu \mathrm{L}$ scale ( 180 $\mu \mathrm{L}$ of headspace) obtained after chain extension of the isolated $\mathrm{PMA}_{42}$ macroinitiator via oxygen tolerant photoinduced Cu-RDRP.

aliquot of EGA, inconsistent results were obtained. In particular, the conversion of the second block was either minimal, if any, (0-10\%) or exhibited a significant tailing to low molecular weights indicating severe termination events (data not shown). This was rather surprising since both MALDI-ToF and ${ }^{1} \mathrm{H}$ NMR showed bromine terminated polymer chains prior to chain extension. It was thus hypothesized that the additional oxygen (either dissolved in the second aliquot of monomer and/or added upon removal of the lid) introduced to the system via the addition of the second monomer was detrimental for preserving high end-group fidelity. To confirm whether this is the case, PMA with DP $=42$ was synthesized and isolated prior to chain extension (Fig. S13†). Upon re-subjecting the $\mathrm{PMA}_{42}$ macroinitiator to irradiation in a fully filled vial insert, in the presence of EGA, well-defined block copolymers of $\mathrm{P}(\mathrm{MA})_{42}-b-\mathrm{P}$ $(\mathrm{EGA})_{42}$ could be obtained with the molecular weight distribution shifting to higher molecular weights and negligible tailing observed. Importantly, the final dispersity was $\sim 1.15$ and the control over the molecular weight distributions was not compromised $\left(M_{\mathrm{n}, \mathrm{SEC}}=10200\right)$ even at near quantitative conversions (99\%) (Fig. 5b and Fig. S14†). An identical chain extension experiment was also performed in the presence of significant headspace $(20 \mu \mathrm{L}$ per $200 \mu \mathrm{L})$. Despite the extent of the headspace, a complete shift of the macroinitiator was evident through SEC analysis $\left(M_{\mathrm{n}, \mathrm{SEC}}=10900\right)$ yielding diblock copolymers with low dispersity value $(D \sim 1.12)$ and high conversion (99\%) (Fig. 5c). Thus, in DMSO, successful chain extensions with or without headspace can be reproducibly achieved by isolating the macroinitiator. These results indicate that, indeed a high proportion of $\omega$-bromo functionality can be maintained and that the unsuccessful in situ chain 
extensions can be explained by the inclusion of additional oxygen through the addition of the second monomer.

To explore the robustness of our oxygen tolerant photoinduced $\mathrm{Cu}-\mathrm{RDRP}$ for the synthesis of well-defined materials on a high-multigram scale, we initially attempted to scale up the polymerization of MA in DMSO ( $100 \mathrm{ml}$ scale, $50 \%$ solids) utilizing a custom made UV box equipped with light bulbs with $\lambda_{\max } \sim 360 \mathrm{~nm}$ (Fig. S15 $\dagger$ ). However, in all our attempts, the septa/lid "popped off" leading to poor monomer conversions and a slightly brown colour attributed to the oxidized catalyst, as a result of the continuous exposure to oxygen. Due to this exothermic nature of the reaction, an exit needle was employed to release the increase in pressure. Although the monomer conversion increased, very high conversions were not achieved and the dispersity was significantly higher $(D \sim 1.3)$ when compared to identical experiments at lower volumes. We then envisaged that TFE might be a better alternative given the high-end-group fidelity of polymers synthesized in TFE as well as the significant thermal stability provided by this solvent. ${ }^{60,61}$ As a result, the polymerization was successfully conducted at $100 \mathrm{~mL}$ (Fig. 6c and Table S2 $\dagger$ ) and $250 \mathrm{~mL}$ (Fig. S16 $\dagger$ ) at high conversions (91-94\%), exhibiting similar initiator efficiency with the lower volume polymerizations and low dispersity values $(D \sim 1.12)$. We also managed to perform the polymerization on a $0.5 \mathrm{~L}$ scale yielding welldefined PMA with narrow molecular weight distributions $(\theta \sim$ 1.19) and high conversions (91\%), thus further highlighting the versatility of the reported approach (Fig. 6d).

\section{Preliminary insights into the oxygen consumption mechanism}

In order to investigate the fate of the dissolved oxygen in the photoinduced $\mathrm{Cu}$-RDRP system an oxygen probe was employed for the in situ $\left[\mathrm{O}_{2}\right]$ monitoring. Under conditions identical to our polymerization $\left([\mathrm{M}]:[\mathrm{I}]:\left[\mathrm{Cu}(\mathrm{II}) \mathrm{Br}_{2}\right]:[\mathrm{L}]=[50]:[1]:[0.02]:[0.12]\right)$ and upon UV irradiation $\left(\lambda_{\max } \sim 360 \mathrm{~nm}\right)$, complete oxygen consumption was observed in $\sim 5$ min (Solution 1) (Fig. 7a). This rapid oxygen consumption can be potentially attributed to the

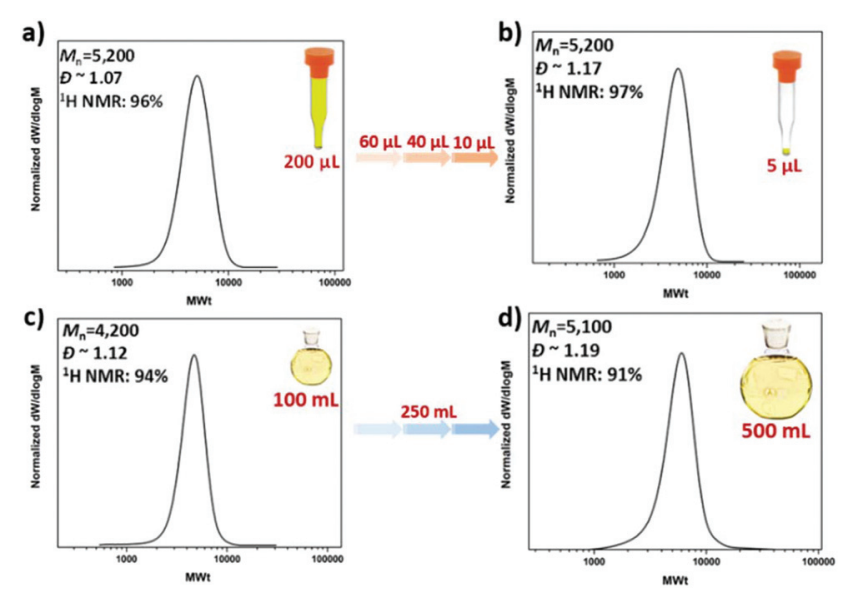

Fig. 6 SEC traces for (a),( b) the low volume $P M A_{50}$ and (c),( d) the high scale $\mathrm{PMA}_{50}$ synthesized via oxygen tolerant photoinduced $\mathrm{Cu}$-RDRP under a UV lamp with broad band $\lambda_{\max } \sim 360 \mathrm{~nm}$.
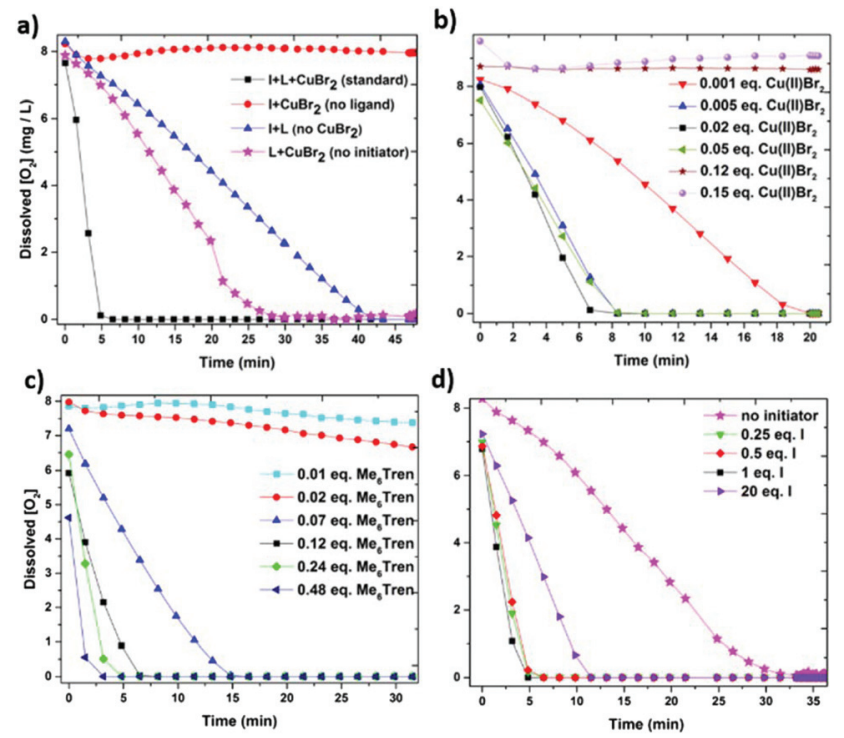

Fig. 7 Graphical illustration of the dissolved oxygen consumption for (a) the standard system (solution 1) and the role of the polymerization components, and the effect of different equivalents of (b) the copper source $\left(\mathrm{Cu}(\Perp) \mathrm{Br}_{2}\right),(\mathrm{c})$ the ligand $\left(\mathrm{Me}_{6}\right.$ Tren) and (d) the initiator (EBiB) on oxygen consumption. All the solutions were exposed under a UV lamp with broad band $\lambda_{\max } \sim 360 \mathrm{~nm}$.

reduction of $\mathrm{Cu}(\mathrm{II}) \mathrm{Br}_{2}$ (by an excess of free amine) to active species $(\mathrm{Cu}(\mathrm{I})$ and/or $\mathrm{Cu}(0))$. The active species can then consume oxygen via two different pathways. In particular, the active species can either react directly with oxygen or abstract the bromine from the initiator leading to the generation of initiating radicals which can then react with oxygen. To investigate this hypothesis, we investigated the role of each component including the copper source $\left(\mathrm{Cu}(\mathrm{II}) \mathrm{Br}_{2}\right)$, the ligand $\left(\mathrm{Me}_{6}\right.$ Tren) and the initiator (EBiB). Initially, the same polymerization mixture (Solution 1) was investigated in the absence of $\mathrm{Cu}(\mathrm{II}) \mathrm{Br}_{2}$. Interestingly, when only initiator and ligand were present, the oxygen consumption was decelerated to $\sim 45 \mathrm{~min}$, thus verifying the importance of $\mathrm{Cu}(\mathrm{II}) \mathrm{Br}_{2}$ to enhance the rate of oxygen consumption. In addition, experiments where the concentration of $\mathrm{Cu}(\mathrm{II}) \mathrm{Br}_{2}$ was altered were also performed (Fig. 7b). At very low $\mathrm{Cu}(\mathrm{II}) \mathrm{Br}_{2}$ concentration (0.001 equiv. with respect to initiator), the oxygen consumption was completed after $\sim 20 \mathrm{~min}$. This is attributed to the slow generation of active species which can then lead to oxygen consumption. However, at higher amounts of $\mathrm{Cu}(\mathrm{II}) \mathrm{Br}_{2}$ (0.005-0.05 equiv.) little, if any, differences in the rate of oxygen consumption were observed ( $\sim 6 \mathrm{~min})$. This suggests that upon sufficient generation of active species, the oxygen consumption can proceed at the maximum rate. It should also be noted that when the concentration of $\mathrm{Cu}(\mathrm{II}) \mathrm{Br}_{2}$ either exceeded or equalled the ligand concentration, no oxygen consumption was observed. This is to be expected as according to the literature, excess of free amine is required to mediate the reduction of the copper complex. ${ }^{64,65}$

We subsequently sought to study the importance of ligand (Fig. 7c). In the absence of ligand, no oxygen consumption was 
evident within a 60 minutes scale, suggesting lack of generated radicals under these conditions. A similar trend was observed when less ligand equivalents than $\mathrm{Cu}(\mathrm{II}) \mathrm{Br}_{2}$ (0.01 and 0.02 with respect to initiator) were employed validating our previous results, in which an excess of ligand is essential to consume oxygen. However, at higher ligand loadings (0.07 w.r.t initiator), oxygen was fully consumed in $\sim 15 \mathrm{~min}$. A further gradual increase of the ligand concentration led to even faster oxygen consumption (as fast as $\sim 3 \mathrm{~min}$ ). It can thus be concluded that (i) an excess of ligand is necessary to consume the oxygen and (ii) more ligand leads to the generation of more active species which can then directly or indirectly consume the oxygen. Finally, in situ $\left[\mathrm{O}_{2}\right]$ monitoring of Solution 1 in the absence of initiator was also conducted. When only $\mathrm{Cu}(\mathrm{II}) \mathrm{Br}_{2}$ and ligand were present, the second fastest oxygen consumption rate (with the first one being the Solution 1 with all the components included) was monitored at $\sim 27 \mathrm{~min}$ (Fig. 7a). This observation verifies our initial hypothesis that the copper complex is primarily responsible for the oxygen consumption. Moreover, by altering the initiator equivalents (Fig. 7d), it can be concluded that when sufficient amount is present, the oxygen consumption remains equally fast $(\sim 5 \mathrm{~min})$ regardless of the initiator concentration ( $0.25,0.5$ and 1 equivalents of initiator). This is reasonable as the complex is the main factor that determines the oxygen consumption and as a result, the same amount of active species generated will only react with a constant amount of initiator, even if further excess of initiator is available. Interestingly, at extremely high initiator loadings (20 equiv. or $\sim 25 \% \mathrm{v} / \mathrm{v}$ ), slower oxygen consumption was observed ( 12 min) which is likely due to the change of the reaction medium.

In summary, from these preliminary experiments it can be inferred that the combination of $\mathrm{Cu}(\mathrm{II}) \mathrm{Br}_{2}$, ligand and initiator synergistically contribute to the oxygen consumption ( $\sim 5 \mathrm{~min}$ ). Upon exclusion of initiator, the second fastest oxygen consumption is being monitored ( $\sim 27 \mathrm{~min})$ which can be predominantly attributed to the reduction of the copper complex into active species. Therefore, the presence of initiator is important to accelerate the rate of consumption suggesting that the initiating radicals react with oxygen more rapidly than the active species. At the same time, in the absence of $\mathrm{Cu}$ (II) $\mathrm{Br}_{2}$, an even slower oxygen consumption is observed ( $45 \mathrm{~min}$ ) which implies that the initiator and the ligand in the absence of copper, are less significant than the complex for the process of oxygen consumption. Although slower, this oxygen consumption can be attributed to either the light-induced $\mathrm{C}-\mathrm{Br}$ bond scission of the initiator (generating initiating/propagating radicals) or by the formation of a radical cation from the ligand upon irradiation. ${ }^{65}$ Finally, since no oxygen consumption is evident in the absence of ligand, it is hypothesized that either the $\mathrm{C}-\mathrm{Br}$ cleavage does not occur at large extent or that the presence of the deactivator is somehow hindering the cleavage even in the absence of ligand (i.e. by delivering the bromine back to the initiator). However, further experiments are required to verify this hypothesis and a more detailed analysis of the mechanism will be the subject of a forthcoming publication.

\section{Conclusions}

In summary, we report the first low volume oxygen tolerant photoinduced $\mathrm{Cu}$-RDRP method independent of complex oxygen scavengers or external deoxygenation methods. Good control over the polymerization and high-end group fidelity were maintained, yielding well-defined homo- and block copolymers with a range of monomers with different hydrophobicity, as well as, semi-fluorinated (meth)acrylates having been successfully polymerized. The facile and efficient nature of this methodology is also applicable to high scale polymerizations (up to $0.5 \mathrm{~L}$ ). Furthermore, the employment of an oxygen probe enabled us to investigate the role of the polymerization components into oxygen consumption. The proposed methodology renders the oxygen-tolerant photoinduced $\mathrm{Cu}$ RDRP a multi-applicable strategy for the synthesis of a range of materials, on different scales with undemanding setup.

\section{Conflicts of interest}

There are no conflicts of interest to declare.

\section{Acknowledgements}

Financial support from the University of Warwick (E. L., R. W., C. E. I., G. P., N. G. E., A. M., G. R. J.), Syngenta (A. M.) and Lubrizol (G. P.) is gratefully acknowledged. R. W. acknowledges the Institute of Advanced Study (University of Warwick) for postdoctoral funding. A.A. acknowledges the Global Marie Curie Fellowship (BINAMA 705041) for financial support. We thank Dr David Fox for his valuable input. We are also grateful for the Polymer Characterization RTP and Dr Daniel Lester (University of Warwick) for providing use of SEC equipment.

\section{References}

1 A. Anastasaki, V. Nikolaou and D. M. Haddleton, Polym. Chem., 2016, 7, 1002-1026.

2 A. Anastasaki, J. Willenbacher, C. Fleischmann, W. R. Gutekunst and C. J. Hawker, Polym. Chem., 2017, 8, 689-697.

3 C. Boyer, N. A. Corrigan, K. Jung, D. Nguyen, T.-K. Nguyen, N. N. M. Adnan, S. Oliver, S. Shanmugam and J. Yeow, Chem. Rev., 2016, 116, 1803-1949.

4 G. R. Jones, A. Anastasaki, R. Whitfield, N. Engelis, E. Liarou and D. M. Haddleton, Angew. Chem., Int. Ed. Engl., 2018, 57, 10468-10482.

5 K. Matyjaszewski, Macromolecules, 2012, 45, 4015-4039.

6 K. Matyjaszewski, Adv. Mater., 2018, 30, 1706441.

7 S. Perrier, Macromolecules, 2017, 50, 7433-7447.

8 B. M. Rosen and V. Percec, Chem. Rev., 2009, 109, 50695119.

9 E. Baeten, J. J. Haven and T. Junkers, Polym. Chem., 2017, 8, 3815-3824. 
10 J. De Neve, J. J. Haven, L. Maes and T. Junkers, Polym. Chem., 2018, 9, 4692-4705.

11 R. Aksakal, M. Resmini and C. R. Becer, Polym. Chem., 2016, 7, 171-175.

12 Y. Abdouni, G. Yilmaz and C. R. Becer, Macromol. Rapid Commun., 2017, 38, 1700212.

13 J.-S. Wang and K. Matyjaszewski, J. Am. Chem. Soc., 1995, 117, 5614-5615.

14 M. Kato, M. Kamigaito, M. Sawamoto and T. Higashimura, Macromolecules, 1995, 28, 1721-1723.

15 V. Percec, T. Guliashvili, J. S. Ladislaw, A. Wistrand, A. Stjerndahl, M. J. Sienkowska, M. J. Monteiro and S. Sahoo, J. Am. Chem. Soc., 2006, 128, 14156-14165.

16 M. R. Hill, R. N. Carmean and B. S. Sumerlin, Macromolecules, 2015, 48, 5459-5469.

17 J. Chiefari, Y. K. Chong, F. Ercole, J. Krstina, J. Jeffery, T. P. T. Le, R. T. A. Mayadunne, G. F. Meijs, C. L. Moad, G. Moad, E. Rizzardo and S. H. Thang, Macromolecules, 1998, 31, 5559-5562.

18 L. Barner, T. P. Davis, M. H. Stenzel and C. BarnerKowollik, Macromol. Rapid Commun., 2007, 28, 539-559.

19 X. Pan, M. A. Tasdelen, J. Laun, T. Junkers, Y. Yagci and K. Matyjaszewski, Prog. Polym. Sci., 2016, 62, 73-125.

20 C. J. Hawker, A. W. Bosman and E. Harth, Chem. Rev., 2001, 101, 3661-3688.

21 V. A. Bhanu and K. Kishore, Chem. Rev., 1991, 91, 99117.

22 S. C. Ligon, B. Husár, H. Wutzel, R. Holman and R. Liska, Chem. Rev., 2014, 114, 557-589.

23 R. Shenoy and C. N. Bowman, Macromolecules, 2010, 43, 7964-7970.

24 J. Yeow, R. Chapman, A. J. Gormley and C. Boyer, Chem. Soc. Rev., 2018, 47, 4357-4387.

25 T. Arakawa, S. J. Prestrelski, W. C. Kenney and J. F. Carpenter, Adv. Drug Delivery Rev., 2001, 46, 307-326.

26 Y. Wang, L. Fu and K. Matyjaszewski, ACS Macro Lett., 2018, 7, 1317-1321.

27 J. Tan, D. Liu, Y. Bai, C. Huang, X. Li, J. He, Q. Xu and L. Zhang, Macromolecules, 2017, 50, 5798-5806.

28 A. E. Enciso, L. Fu, S. Lathwal, M. Olszewski, Z. Wang, S. R. Das, A. J. Russell and K. Matyjaszewski, Angew. Chem., Int. Ed., 2018, 57, 16157-16161.

29 A. E. Enciso, L. Fu, A. J. Russell and K. Matyjaszewski, Angew. Chem., Int. Ed., 2017, 57, 933-936.

30 Y. Lv, Z. Liu, A. Zhu and Z. An, J. Polym. Sci., Part A: Polym. Chem., 2016, 55, 164-174.

31 R. Chapman, A. J. Gormley, K.-L. Herpoldt and M. M. Stevens, Macromolecules, 2014, 47, 8541-8547.

32 R. Chapman, A. J. Gormley, M. H. Stenzel and M. M. Stevens, Angew. Chem., Int. Ed. Engl., 2016, 55, 4500-4503.

33 Q. Yang, J. Lalevée and J. Poly, Macromolecules, 2016, 49, 7653-7666.

34 I.-H. Lee, E. H. Discekici, A. Anastasaki, J. R. de Alaniz and C. J. Hawker, Polym. Chem., 2017, 8, 3351-3356.

35 S. Fleischmann, B. M. Rosen and V. Percec, J. Polym. Sci., Part A: Polym. Chem., 2010, 48, 1190-1196.
36 S. Fleischmann and V. Percec, J. Polym. Sci., Part A: Polym. Chem., 2010, 48, 2243-2250.

37 G. Ng, J. Yeow, J. Xu and C. Boyer, Polym. Chem., 2017, 8, 2841-2851.

38 J. Yeow, R. Chapman, J. Xu and C. Boyer, Polym. Chem., 2017, 8, 5012-5022.

39 G. Ng, J. Yeow, R. Chapman, N. Isahak, E. Wolvetang, J. J. Cooper-White and C. Boyer, Macromolecules, 2018, 51, 7600-7607.

40 A. Anastasaki, V. Nikolaou, A. Simula, J. Godfrey, M. Li, G. Nurumbetov, P. Wilson and D. M. Haddleton, Macromolecules, 2014, 47, 3852-3859.

41 M. Chen, M. Zhong and J. A. Johnson, Chem. Rev., 2016, 116, 10167-10211.

42 N. Corrigan, J. Yeow, P. Judzewitsch, J. Xu and C. Boyer, Angew. Chem., Int. Ed., 2018, DOI: 10.1002/anie.201805473.

43 J. Xu, K. Jung, A. Atme, S. Shanmugam and C. Boyer, J. Am. Chem. Soc., 2014, 136, 5508-5519.

44 J. Yeow, S. Joshi, R. Chapman and C. Boyer, Angew. Chem., Int. Ed. Engl., 2018, 57, 10102-10106.

45 J. Xu, S. Shanmugam, H. T. Duong and C. Boyer, Polym. Chem., 2015, 6, 5615-5624.

46 S. Shanmugam, J. Xu and C. Boyer, J. Am. Chem. Soc., 2015, 137, 9174-9185.

47 Q. Fu, K. Xie, T. G. McKenzie and G. G. Qiao, Polym. Chem., 2017, 8, 1519-1526.

48 K. Borská, D. Moravčíková and J. Mosnáček, Macromol. Rapid Commun., 2017, 38, 1600639.

49 Z. Huang, C. Feng, H. Guo and X. Huang, Polym. Chem., 2016, 7, 3034-3045.

50 J. Mosnáček, A. Eckstein-Andicsová and K. Borská, Polym. Chem., 2015, 6, 2523-2530.

51 X. Pan, S. Lathwal, S. Mack, J. Yan, S. R. Das and K. Matyjaszewski, Angew. Chem., Int. Ed., 2017, 56, 27402743.

52 E. Liarou, R. Whitfield, A. Anastasaki, N. G. Engelis, G. R. Jones, K. Velonia and D. M. Haddleton, Angew. Chem., Int. Ed., 2018, 57, 8998-9002.

53 G. R. Jones, R. Whitfield, A. Anastasaki, N. Risangud, A. Simula, D. J. Keddie and D. M. Haddleton, Polym. Chem., 2018, 9, 2382-2388.

54 R. B. Smail, R. L. Jezorek, J. Lejnieks, M. Enayati, S. Grama, M. J. Monteiro and V. Percec, Polym. Chem., 2017, 8, 31023123.

55 L. Voorhaar, S. Wallyn, F. E. Du Prez and R. Hoogenboom, Polym. Chem., 2014, 5, 4268-4276.

56 M. Enayati, R. L. Jezorek, M. J. Monteiro and V. Percec, Polym. Chem., 2016, 7, 3608-3621.

57 R. Whitfield, A. Anastasaki, G. R. Jones and D. M. Haddleton, Polym. Chem., 2018, 9, 4395-4403.

58 E. H. Discekici, A. Anastasaki, R. Kaminker, J. Willenbacher, N. P. Truong, C. Fleischmann, B. Oschmann, D. J. Lunn, J. Read de Alaniz, T. P. Davis, C. M. Bates and C. J. Hawker, J. Am. Chem. Soc., 2017, 139, 5939-5945.

59 S. R. Samanta, R. Cai and V. Percec, Polym. Chem., 2014, 5, 5479-5491. 
60 V. Nikolaou, A. Anastasaki, F. Brandford-Adams, R. Whitfield, G. R. Jones, G. Nurumbetov and D. M. Haddleton, Polym. Chem., 2016, 7, 191-197.

61 A. Anastasaki, B. Oschmann, J. Willenbacher, A. Melker, M. H. C. Van Son, N. P. Truong, M. W. Schulze, E. H. Discekici, A. J. McGrath, T. P. Davis, C. M. Bates and C. J. Hawker, Angew. Chem., Int. Ed., 2017, 56, 14483-14487.
62 T. Y. Lee, C. A. Guymon, E. S. Jönsson and C. E. Hoyle, Polymer, 2004, 45, 6155-6162.

63 J. G. Riess, Tetrahedron, 2002, 58, 4113-4131.

64 T. G. Ribelli, D. Konkolewicz, S. Bernhard and K. Matyjaszewski, J. Am. Chem. Soc., 2014, 136, 13303-13312.

65 E. Frick, A. Anastasaki, D. M. Haddleton and C. BarnerKowollik, J. Am. Chem. Soc., 2015, 137, 6889-6896. 